\title{
The Malay Traditional Food Preparation
}

\author{
Mohd Shazali Md. Sharif1 , Norazmir Md Nor² Salehuddin Mohd Zahari', \\ Mohammad Halim Jeinie ${ }^{2}$ \\ ${ }^{1}$ Faculty of Hotel \& Tourism Management, \\ ${ }^{2}$ Faculty of Health Sciences, \\ Universiti Teknologi MARA, 42300 Puncak Alam, Selangor, Malaysia \\ shazali@salam.uitm.edu.my
}

\begin{abstract}
Global modernization, food technology and time constraint becomes the reasons why youngest generation is choosing ready-to-eat food rather than preparing traditional foods. Even the traditional kuih-muih until the main dishes, the preparations are relying on the elder. The purpose of this study is to determine the reasons why the young generation had limited skills and knowledge in the Malay traditional food preparation. The ethnography technique has been used to document all the activities of food preparation. Consequently, upgrading young generation skills and knowledge helps to preserve Malay traditional foods that become one of the most valuable knowledge.
\end{abstract}

Keywords: food knowledge, cooking skills, traditional foods, social interactions

eISSN: 2398-4279 @ 2017. The Authors. Published for AMER ABRA by e-International Publishing House, Ltd., UK. This is an open access article under the CC BY-NC-ND license (http://creativecommons.org/licenses/by-ncnd/4.0/). Peer-review under responsibility of AMER (Association of Malaysian Environment-Behaviour Researchers), ABRA (Association of Behavioural Researchers on Asians) and cE-Bs (Centre for EnvironmentBehaviour Studies), Faculty of Architecture, Planning \& Surveying, UniversitiTeknologi MARA, Malaysia. https://doi.org/10.21834/ajqol.v2i7.63 


\subsection{Introduction}

In this globalization era, most of the young generations depend on the application of science and technology in their life. From the communication, education and nutrition, everything must be up to date, and this happens to the food industries in Malaysia. Nowadays, the Malay young generation had limited skills and knowledge in their traditional food. Even the traditional kuih-muih until the main dishes, most of the young generations are just relying on their mothers to prepare the delicacies. Despite that, the issue on lack of skills and knowledge in traditional foods is brought up so that the young generation always aware that the Malay traditional foods would be quickly forgotten if the concept of continuity if it is not practiced in their daily life.

The problem statement for this study is the reasons of the young generation had limited skill and knowledge in the Malay traditional food preparation. As we compared the Malay young generation during our grandmother's century with a young generation nowadays, the gap of different is getting wider. If we were to compare, almost all young generation during old centuries knew the basic traditional food cooking skills and the continuity they get from their late grandmothers or mothers, but the young generation today had limited skill in cooking preparation especially in Malay traditional food. They prefer to buy the traditional food from the market or stall compared than learning how to make it from the mothers or eldest. The common reasons the young generation did not interest are because of lack of knowledge about the important of learning traditional food preparation, lack of time because too busy, difficult to find raw materials, time-consuming during processing and others. Besides that, the young generation nowadays also more focuses on academic, and career performance compared than gain knowledge in the cooking skill. Because of those reasons, this research focuses on analyzing what makes the limited skill and knowledge of the young generation in the Malay traditional food preparation and the discussion for these problems.

The objective of this study is to find out what makes the Malay younger generation nowadays had limited skills and knowledge in preparing Malay traditional food. This study will show the participation and involvement of the young generation in food preparation process and also their skills by observing or learning from their elders whom usually from the mother or grandmother. Through this study also the reason or factors involve that causing the lack of involvement, knowledge and skills by the young generation in the traditional food preparation can be identified.

\subsection{Methodology}

This study applied an observation and ethnographic technique to highlight on Malay traditional food preparation. Ethnography is used to define the problems that are not explicitly stated yet. To determine the participants, include together with the boundaries or obstacles of the study population that are not identified or known. To explore the reasons or factors involve the problem to identify, understand and address them by intervention or 
research studies. Ethnography is also used to document the process and identify or describe outcomes and also designing suitable measures to the problems (Goodson \& Vassar, 2011),

The techniques used to obtain the result from this study are through picture taking, observation and interview session. The observation and helping process took place during Malay festive which is Eid Adha in October 2013. The participants are observing and helping their mother to prepare the traditional food starting from preparing the ingredients until the dishes are served in the morning. The mother of four Malay families from different states engaged in the research study done with camera assistants to capture the pictures of the significant moments during the observation and preparation of the Malay traditional foods. The traditional dishes are from two different states which are Sarawak and Kelantan. In this study, the observation is more emphasis on the limitation skills and knowledge of Malay young generation in Malay traditional food preparation.

The approach employs in the process were written in a log book before being analyzed further. The pictures that were snapped during the food preparation process were used as evidence for report, analysis and complete the research. A log book is one of necessary tools and also as a reference because each step and situation happened in the Malay traditional food preparation must be reported. This observation and the child helping the mother to prepare Malay traditional food are taking almost one day before Eid Adha. On that day, the primary participant focus is on the ingredients, steps of food preparation, problems and difficulty while helping in making the traditional food process, and also the advantages obtained from helping the mother. The participant had involved and helped the mother to serve the traditional dishes on Eid Adha. The experiences that the participant gained help a lot in analyzing and writing this research.

\subsection{Results and Discussions}

Nowadays, the young generation is more dependent on the technology for food preparation. Apart from that, a young generation mostly buys ready to eat food that is more convenient and simple. To prepare the traditional foods, the most concerning matter is to find the raw ingredients. As for people in Sarawak, the eldest have adequate skills to find natural resources such as plants and herbs. But after the modernization begin, the young generation thought to be less interested to prepare traditional foods

\subsection{Lack of Skills}

For instance, the most famous delicacy in Sarawak ethnic people is kelupis, a Kedayan's traditional food that is made from glutinous rice. The preparation is not complicated, but the sources of raw ingredients are very difficult to find. Mostly, the raw ingredients such as Irik leaves and coconut milk are found at a fresh market. But previously, the ancestors usually went to the forest to find the source by collecting fresh leaves and choosing the best 
coconut to get the coconut milk. But in this globalization era, the young generation had limited skills to select the best raw ingredients for the traditional food preparation. Thus, in this study, the research will expose the contribution by the young generation in the preparation of this traditional food called kelupis, from the beginning of cooking until food presentation.

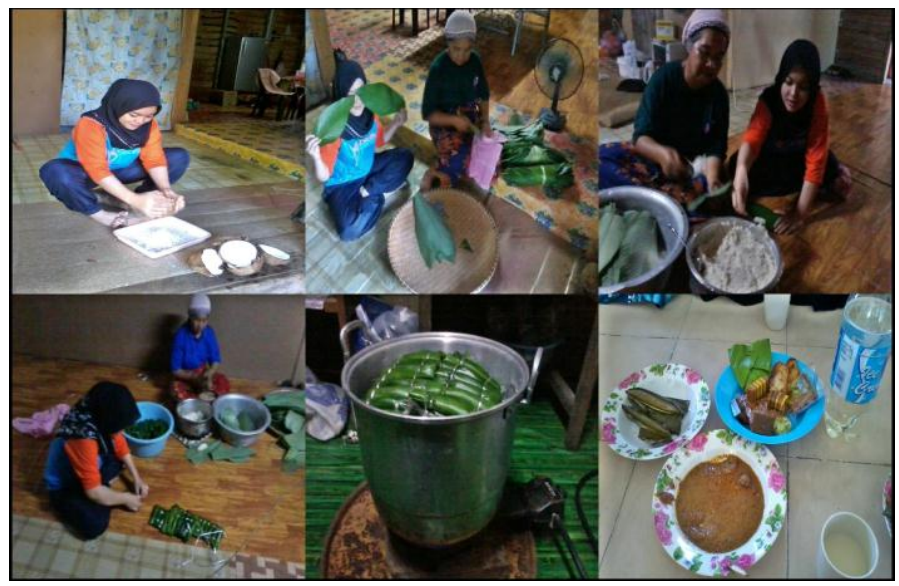

Fig. 1. Clockwise rotation, the upper figure showing that the daughter was helping her mother although she does not have skills in the traditional food preparation kelupis. The lower figure shows that final product of the kelupis and the way of food being presented.

\subsection{Lack of Exposure}

Figure 2 shows the preparation process to make ketupat that is one of the common Malay traditional foods done by both of the mother and daughters for Eid Adha's celebration. During the food preparation, the daughter fully observed her mother and the steps on how to make it while learning about it in the process. The daughter mostly just observed and helping her mother on the simple work or task instead of preparing the food by herself without the assistant of the mother.

There are several reasons for the lack of exposure and involvement of the daughter and the younger generation in the kitchen, especially for traditional food preparation. The lack of interest to prepare traditional food are also one of the reasons as younger generation nowadays prefer to eat western or other modern food which seems to be more attractive to them. Traditional foods are sometime tricky to make that can cause the daughter or any other younger generation reluctant to involve in making the dishes compare to other types of food. Besides that, nowadays most of the traditional foods are usually made during the festive celebration only and not that often which may cause less exposure to such food preparation to the younger generation. 


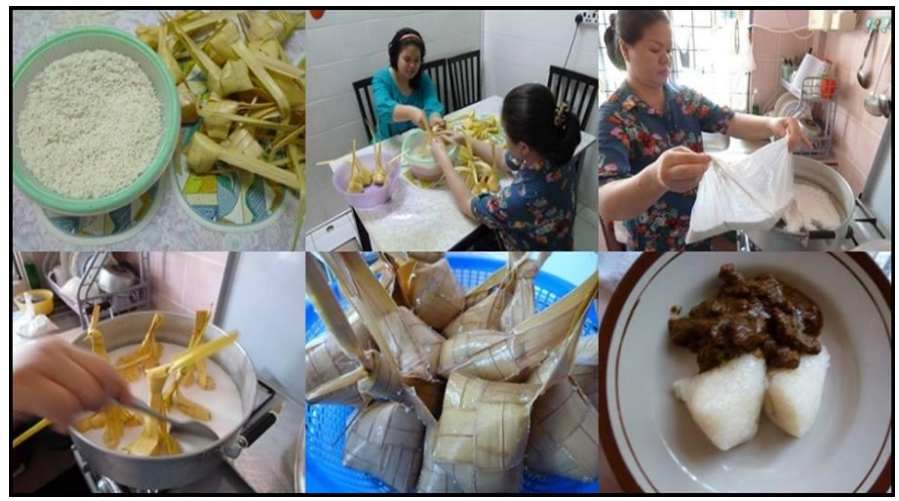

Fig. 2. The process of making ketupat by both of the mother and daughters. The daughter mostly observed her mother and assisted in an easy task in preparing the food.

Sometimes, some mothers prefer to work and cook alone in the kitchen because in their opinion it is faster to do it alone than more hands involve together, and this unconsciously encourage for the lack of involvement of their child in the kitchen. These all can lead to the lack of skills and knowledge of younger generation nowadays on preparing Malay traditional food. As seen in the pictures above in Figure 2, through the process, the daughter have learn a lot on the steps to make the ketupat correctly which is due to the exposure and involvement in the kitchen by working besides her mother throughout the day from the start to the end of the day.

\subsection{Time Consuming}

Figure 3 shows the preparation process to make Malay traditional food that is done by both of the mother and daughters for Eid Adha's celebration. The young generation always thinks that the traditional food preparation is time-consuming, and they do not want to waste their time by gaining the knowledge on that food. This can be proved by the activity of making ketupat palas in Kelantan, Malaysia as the pictures shown above. In the festive season, ketupat palas are usually made by eldest generation because the preparation of making the ketupat itself is complicated. The process is starting from the palas leaves must be joined until it become like a pod and later to be filled with steamed glutinous rice. The mother is trying to show steps by steps to make sure the daughter understands and can gain the skills correctly.

Most of the young generation lacks patience while waiting for the cooking process because it takes hours to complete it. The step of fills the ketupat pod with steamed glutinous rice is completely done by eldest generation as this step is difficult a part and needs some patience and skills. Since the process of making Malay traditional food is taking too long, many young generations nowadays prefer to buy many types readymade 
traditional foods that sold at the stall usually before the festive day. This practice showed our generation became lazy because they are too busy with other responsibilities and do not have time to spend on learning and gain knowledge in making Malay traditional food. Nowadays the elders are usually the one with the most skills and knowledge to prepare traditional foods. Even the young generations are still depending on their elder family members to lead the process of cooking during festive celebration or wedding feast. Not many people in the past further their studies at the higher level especially the young ladies. They start learning how to manage house works including cooking since a young age. But now, the perception has utterly changed. Not all children are interested to assist their mothers at the kitchen. Even the parents nowadays are encouraging their children to further their study and learning how to live far from home.

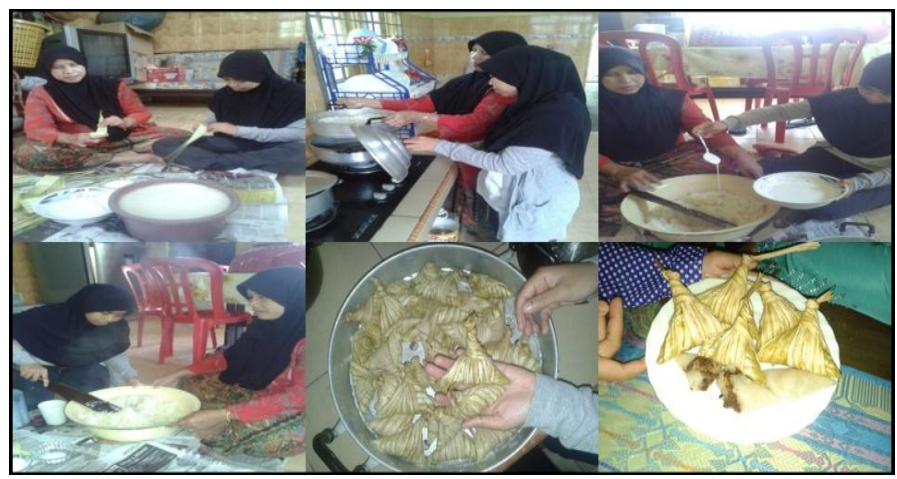

Fig. 3. The upper figure shows the mother teaches her daughter how to prepare ketupat palas. The lower figure shows that the final product of ketupat palas.

\subsection{Time limitation}

Thus, when this situation goes on, they will be busier with their study and have limited time to learn cooking skills from older family members. If someone who has spent his/her studies years in boarding school and then living in the hostel during degree years, does he/she really have the time to spend learning the skills to prepare traditional foods from their mother or grandmother? They might sometimes help but if they do not practice the skills frequently, they can easily forget it.

As seen in Figure 4, the daughter finds it hard to handle all the cooking by her. Most of the works were done by the mother and observed by the daughter. The daughter helped by following instructions from the mother. If the daughter had spent more time helping and practicing how to prepare the dish, then she should have been able to prepare the dish alone. That is without a mother to explain what to do at every step of the cooking process. Moreover, the dish prepared in the figure is ayam masak merah that is quite a common dish, and it is also eaten during the non-festive season. 


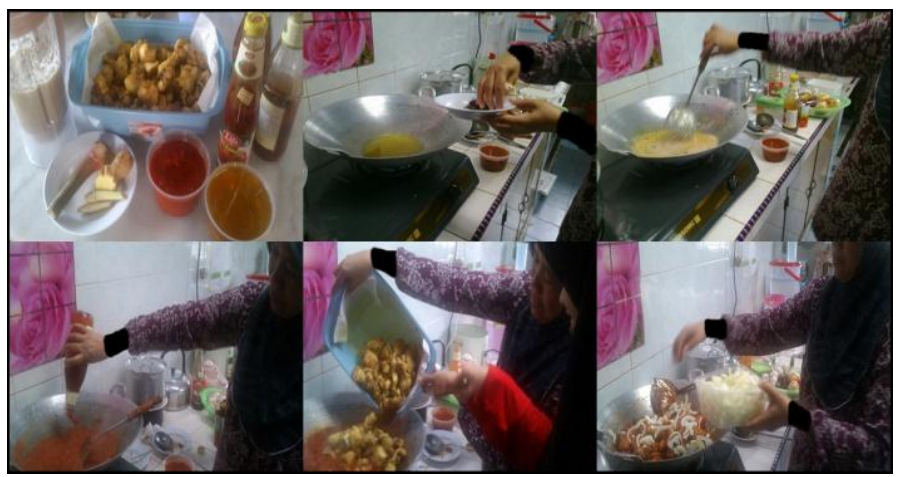

Fig. 4. Clockwise rotation, the upper figure shows that the mother teaches her daughter to prepare ayam masak merah. The mother did the job from the beginning until the end and watched by her daughter.

The opportunities to obtain the knowledge and skills of preparing traditional foods from the elder generations should not be missed. Traditional foods can represent our background, and it is such a precious heritage. Being educated is important but it is also important for parents to prepare their children on the skills that are useful for life and can be passed to the next generations. There are some factors that contribute to the fact where the young generations have low knowledge and skills in preparing traditional foods. The factors are the lack of skills, lack of exposure to the cooking processes, low interest in trying because the cooking process is time-consuming and also a limitation in time to learn from the experts. Modern generations are known as the generation of the technology era; they prefer things that are fast and easy to be prepared.

Thus, to encourage the young generation to gain more skills and knowledge on the traditional food preparation, young generation need to have the desire to learn about their heritage. They should be more passionate to be having the skills in preparing Malay traditional foods. Besides that, the parents or elders should give first exposure to their child and encourage the child involvement in the traditional food preparation process at an early age. This is one of the methods that are useful for the transmission of knowledge and skills to take place from generation to generation. The Malay modern society should spend some time to gain the experience themselves how to prepare the foods although it might take a long time, but it is worth the time. Young generations who may have limited time due to study or work should realize that it is important to have a lot of skills other than just excellence in academic. 


\subsection{Conclusion}

As a conclusion, the young generations have a small interest and desire to learn about traditional foods. The young generations have started to neglect their culture. From the study, the participants have realized how they are not aware of much knowledge they should have got from their elders if they spend more time and effort to help in the kitchen. Furthermore, by involving more in the cooking process of traditional foods the young generations get to be closer to the older family members.

\section{Acknowledgement}

This research was funded by the Ministry of Higher Education, Malaysia through Universiti Teknologi MARA under RAGS grant: 600-RMI/RAGS 5/3 (179/2012). HS227/5 students have assisted this study: Alifah Farhanah Massalleh, Arnieta Aikni, Nur Aizlynna Muhamad and Siti Nurul Aini Mohamed Yusoff (HS227/5 students, academic year 2012/13). Also to the respondents and key informants who shared their knowledge and experience: Madam Sani Jali, Madam Razuyah Kipli, Madam Faraziela Abdullah, Madam Kamariah Zakaria and Sarawak, Kelantan communities and other individuals involved in this study.

\section{References}

Caraher, M., Dixon, P., Lang, T., \& Carr-Hill, R. (1999). The state of cooking in England: the relationship of cooking skills to food choice. British Food Journal, 101(8), 590-609. doi:10.1108/00070709910288289

Chiok, P. F., Low, C. C., \& Ang, S. M. (2012). Malaysian Culture : Views of Educated Youths about Our Way Forward, 4662323(0), 1-5. doi:10.7763/IPEDR.

Dilis, V., Vasilopoulou, E., Georga, K., Trichopoulou, a, \& Soukara, S. (2006). Traditional foods: Why and how to sustain them. Trends in Food Science \& Technology, 17(9), 498-504. doi:10.1016/j.tifs.2006.03.005

Goodson, L., \& Vassar, M. (2011). An overview of ethnography in healthcare and medical education research. Journal of educational evaluation for health professions, 8, 4. doi:10.3352/jeehp.2011.8.4

Kwik, J. (2008). Traditional Food Knowledge : A Case Study of an Immigrant Canadian "Foodscape ", 36(1).

Lipski, E. (2010). Traditional non-Western diets. Nutrition in clinical practice : official publication of the American Society for Parenteral and Enteral Nutrition, 25(6), 585-93. doi:10.1177/0884533610385821

Melissa N Laska, Nicole I Larson, Dianne Neumark-Sztainer and Mary Story ,2012, Does involvement in food preparation track from adolescence to young adulthood and is it associated with better dietary quality? Findings from a 10-year longitudinal study. Public Health Nutrition, 15, pp 1150-1158. doi:10.1017/S1368980011003004.

Muhammad, N. H., Ab. Karim, M. S., Othman, M., \& Ghazali, H. (2013). Relationships of Socioeconomic Level with Eating Behavior of Traditional Food among Adolescents. Mediterranean Journal of Social Sciences, 4(11), 13-20. doi:10.5901/mjss.2013.v4n11p13 
Sharif, M. S. M., Nor, N. M., \& Zahari, M. S. M. (2013). The Effects of Transmission of Malay Daily Food Knowledge on the Generation Practices. Procedia - Social and Behavioral Sciences, 85(2004), 227-235. doi:10.1016/j.sbspro.2013.08.354

Sinead Furey, Heather Mcllveen, Christopher Strugnell and Gillian Armstrong, (2000) "Cooking skills: a diminishing art?", Nutrition \& Food Science, Vol. 30 Iss: 5, pp. -

Symons, Michael. "Cooking." Encyclopedia of Food and Culture, 2003, Retrieved November 18, 2013 from http://www.encyclopedia.com/doc/1G2-3403400161.html 